\title{
Bethanechol versus selegiline in amelioration of spinal cord injury in a rat model: A potential therapeutic option in spinal cord injury treatment
}

\author{
Guangliang Fan ${ }^{1}$, Jinli Luan ${ }^{1}$, Xiankuo Tang ${ }^{2}$, Qimin Song ${ }^{3 *}$ \\ ${ }^{1}$ Department of Neurosurgery, Longkou Nanshan Health Valley Cancer Hospital, Longkou City, Shandong Province 265700, \\ ${ }^{2}$ Department of Neurosurgery, Dongping County People's Hospital, Tai'an City, Dongping County 271500, ${ }^{3}$ Department of \\ Neurosurgery, Linyi People's Hospital, Linyi, Shandong Province 276003, China
}

*For correspondence: Email: sarahglennnde@yahoo.com; Tel: 0086-0539-8312972

Sent for review: 31 May 2019

Revised accepted: 19 December 2019

\begin{abstract}
Purpose: To compare the effect of bethanechol versus selegiline in ameliorating spinal cord injury (SCl) in a rat model.

Methods: Male adult Wistar rats $(200-250$ g) were equally divided into 3 groups: test (SCl rats treated with bethanechol), and control reference (SCl rats treated with selegiline) and control (SCl rats treated with vehicle). SCl was induced in the rats using the clipping method. Thereafter, motor function was assessed in the rats using a rotarod. Each rat was sacrificed by decapitation, and the cortex was excised for use in the study of the involvement of cholinergic and monoaminergic transmission in SCl rats using real-time quantitative polymerase chain reaction and western blot analysis.

Results: Retention time was numerically greater in rats treated with acetyl choline agonist at all rotations (10, 15 and $25 \mathrm{rpm})$ when compared to MAO A inhibitor group, but the difference was not statistically significant $(p>0.05)$. Both bethanechol and selegiline improved motor function by increasing cholinergic and monoaminergic transmission. Both drugs (bethanechol and selegiline) were effective in ameliorating the motor function deficit caused by spinal cord injury. A significant upregulation in acetylcholine esterase (AChE) was observed in the cortex of the SCl rats, relative to non-SCl rats $(p<$ 0.005). Results from cholinergic receptor binding studies revealed significantly decreased Bmax and kd values for muscarinic receptors in $\mathrm{SCl}$ rats, when compared to non-SCl rats. Moreover, the reduction in the intensity of cholinergic receptors was significantly higher in the cerebral cortex of SCl rats than in non-SCl rats.

Conclusion: Bethanechol and selegiline are effective in ameliorating motor function deficit caused by spinal cord injury in rats. Both drugs also improve motor function in $\mathrm{SCl}$ rats. Therefore, the drugs have potentials for use in the therapeutical management of spinal cord injury.
\end{abstract}

Keywords: Spinal cord injury, Bethanechol, Selegiline, Motor functions, Monoaminergic transmission, Cholinergic transmission

This is an Open Access article that uses a fund-ing model which does not charge readers or their institutions for access and distributed under the terms of the Creative Commons Attribution License (http://creativecommons.org/licenses/by/4.0) and the Budapest Open Access Initiative (http://www.budapestopenaccessinitiative.org/read), which permit unrestricted use, distribution, and reproduction in any medium, provided the original work is properly credited.

Tropical Journal of Pharmaceutical Research is indexed by Science Citation Index (SciSearch), Scopus, International Pharmaceutical Abstract, Chemical Abstracts, Embase, Index Copernicus, EBSCO, African Index Medicus, JournalSeek, Journal Citation Reports/Science Edition, Directory of Open Access Journals (DOAJ), African Journal Online, Bioline International, Open-J-Gate and Pharmacy Abstracts

\section{INTRODUCTION}

Spinal cord injury (SCl) is one of most common reasons for disability worldwide. Therefore, understanding $\mathrm{CNS}$ pathways after $\mathrm{SCl}$ is a key to establishing an accurate treatment [1]. In motor cortex, changes in neurotransmitter are helpful for the accurate understanding of brain- 
spinal cortex synchronization in SCl. The muscarinic receptors in CNS regulate learning and memory, and are also involved in controlling several sensory, motor, and autonomic routes. Muscarinic acetylcholine receptor plays a vital role in the functioning of sensory and motor structures [2]. Also, role of monoamine oxidases (MAO) in controlling sensory, motor, and autonomic routes have been well-documented [3-5]. A published study showed that monoamine oxidase-B inhibitor protects degenerating spinal neurons, which enhances nerve regeneration and functional recovery in sciatic nerve crush injury model $[6,7]$.

It was hypothesized that inhibition of monoamine oxidase- $\mathrm{B}$ may improve the $\mathrm{SCl}$ recovery by increasing level of NA and $5 \mathrm{HT}$ in brain or spinal cord area. Also, hypothesized that activation of muscarinic receptor in brain and spinal cord may improve recovery of $\mathrm{SCl}$ by increasing cholinergic transmission in CNS. There is no study evaluating and comparing the effect of bethanechol (muscarinic receptor agonist) and selegiline (mono-amine. oxidase inhibitor type $B$ [MAOB-I]) in amelioration of spinal cord injury in rat model of spinal cord injury. Thus, the present study was designed to compare the effect of Bethanechol versus Selegiline in amelioration of spinal cord injury (SCl) in a rat model.

\section{EXPERIMENTAL}

A total of 60 male adult Wistar rats $(200-250 \mathrm{~g})$ were equally divided into 23 groups: test (SCl rats treated with Bethanechol $[0.6 \mathrm{mg} / \mathrm{kg} / \mathrm{day}]$ ), and control reference (SCl rats treated with Selegiline [2.5 $\mathrm{mg} / \mathrm{kg}$ ) intraperitoneally) and control (SCl rats treated with Vehicle) were housed in isolated cages with 12-h day/12-h night light cycle, with ad libitum access to rat feed and drinking water. The study protocol was approved by the animal ethics committee of Linyi People's Hospital vide approval number: IRB/LPH/09/82A-2018 and the CPCSEA guidelines were followed for animal care in all the study-related procedures [8]. Rats of all groups were treated for 10 days. Chronic SCl was induced using the clipping method. Each rat was sacrificed using decapitation, and the cortex was dissected and stored at $-80{ }^{\circ} \mathrm{C}$ prior to assays.

Motor function of the rats was tested using rotarod test following the induction of $\mathrm{SCl}$. In this test, each rat was trained 5 times before taking actual reading to assess its motor function. The actual reading was recorded for each rat at different speeds (rpm): low (10 rpm), medium 15 rpm, and high/fast (25). In addition, retention time was measured at these rpm values in both groups. Motor function was assessed using Basso Beattie and Bresnahan motor rating scale" at baseline, day 7 and day 14. Also, pain was assessed by mechanical allodynia at baseline, day 7 and day 14. Real-time PCR assay was conducted in 96-well kits in a PCR instrument. The RT-PCR assay was performed using the primers for $\mathrm{MAO}$, with RT- $\beta$-actin as internal control. Total protein (approx. $50 \mu \mathrm{g}$ ) was extracted from cells or tissues of cortex and fractionated using $10 \%$ SDS-polyacrylamide gel electrophoresis. The bands were then transferred to nitrocellulose membrane, and images were captured using Odyssey Infrared Imaging System. The loading control was glyceraldehyde 3-phosphate dehydrogenase (GAPDH).

Cortex was dissected and was sliced into different sections using cryostat. Each section of dissected cerebral cortex was treated with phosphate buffer at $\mathrm{pH} 7.4$ for half an hour, and then incubated with muscarinic and nicotinic acetylcholine receptor antibody. The expressions of cholinergic and monoamine oxidase receptors were evaluated using pixel intensity technique. Receptor-binding was determined using Scatchard method for assessment of receptor binding variables such as $B_{\max }$ (maximum binding), and $\mathrm{k}_{\mathrm{d}}$ (dissociation constant). Usually, $B_{\max }$ is used to measure expression of receptors available in cortex sample, while $k_{d}$ is an index of the affinity of the muscarinic and nicotinic receptors for ligands.

\section{Statistical analysis}

No formal sample size was calculated since the present investigation was a preliminary investigation. Comparison of retention times, locomotor function score, pain threshold and the expressions of cholinergic and monoamine oxidase receptors in cortical region between both groups were analyzed using appropriate statistical method such as student $t$-test. Data related to receptor binding analysis in cortex between both groups were analyzed using nonparametric test. The pixel intensities in the cortex between both groups were analyzed using nonparametric test. Statistical analysis of data was performed using SPSS 25.0 statistical analysis software. Level of statistical significance was 0.05 .

\section{RESULTS}

In rotarod test, retention times (seconds) were significantly less in rats treated with vehicle when compared to rats treated with acetyl choline agonist and MAO A inhibitor. Retention times (seconds) were significantly greater in acetyl 
choline agonist and MAO A inhibitor group as compared to control group treated with vehicle. On comparing acetyl choline agonist and MAO A inhibitor group, retention times (seconds) was numerically greater in rats treated with acetyl choline agonist at all rotations (10, 15 and 25 rpm) when compared to MAO A inhibitor group. However, the difference between acetyl choline agonist and MAO A inhibitor group was not statistically significant $(p>0.05)$.

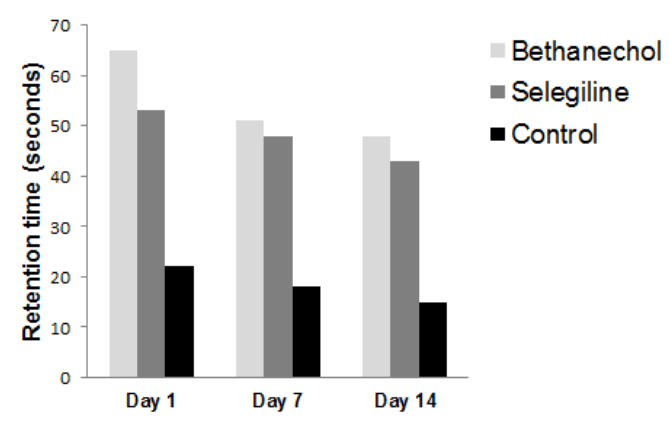

Figure 1: Retention time in rats treated with vehicle, acetyl choline agonist and MAO A inhibitor group; $p<$ 0.005 for Vehicle vs acetyl choline agonist and MAO A inhibitor group

In BBB scale, locomotor function was significantly impaired in rats treated with vehicle when compared to rats treated with acetyl choline agonist and MAO A inhibitor. Locomotor function was significantly improved in rats treated with acetyl choline agonist and MAO A inhibitor group when compared to control that were treated with vehicle. On comparing, acetyl choline agonist and MAO A inhibitor group, it was observed that improvement in locomotor function was numerically greater in rats treated with acetyl choline agonist as compared to MAO A inhibitor group. However, difference between acetyl choline agonist and MAO A inhibitor group was not statistically significant $(p>0.05)$.

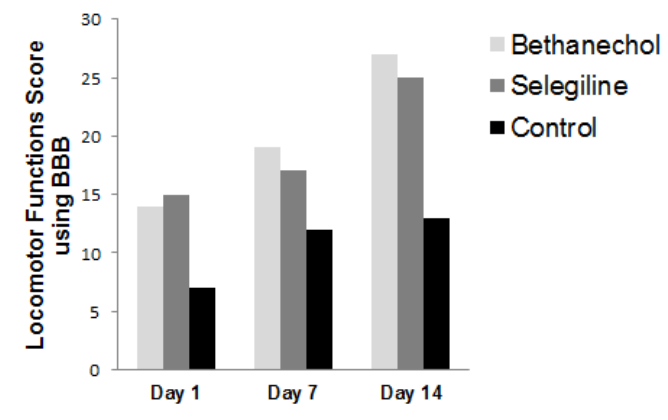

Figure 2: Locomotor function in rats treated with vehicle, acetyl choline agonist and MAO A inhibitor group; $p<0.005$ for vehicle vs acetyl choline agonist and MAO A inhibitor group

Similar results were observed for pain threshold. Pain threshold was significantly greater in rats treated with acetyl choline agonist and MAO A inhibitor, when compared to rats treated Vehicle (Figure 3). It was observed that pain threshold was numerically greater in rats treated with acetyl choline agonist as compared to MAO A inhibitor group. However, difference between acetyl choline agonist and MAO A inhibitor group was not statistically significant $(p>0.05)$.

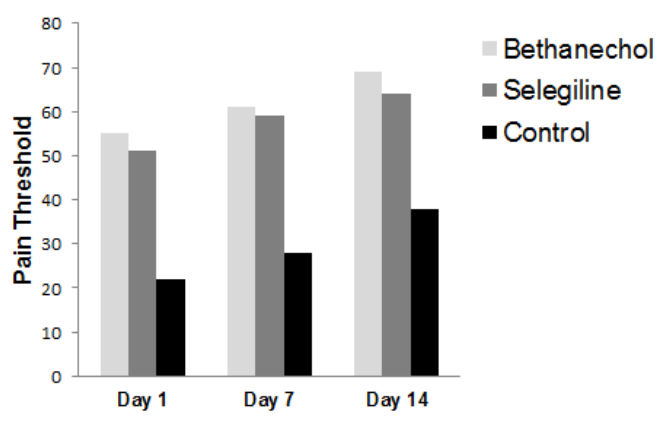

Figure 3: Pain threshold in rats treated with vehicle, acetyl choline agonist and MAO A inhibitor group; $p<$ 0.005 for Vehicle vs acetyl choline agonist and MAO A inhibitor group

RT-PCR analysis showed significantly lower expression of AChE in the cortex region of after treatment with acetyl choline agonist group on day 1 (baseline) and day 14 (after treatment, Figure 4). Similar trend was observed in MAO A inhibitor group. However, after treatment, the expression of MAO was significantly reduced from baseline. This indicates inhibition of MAO enzyme results in improvement in locomotor function.

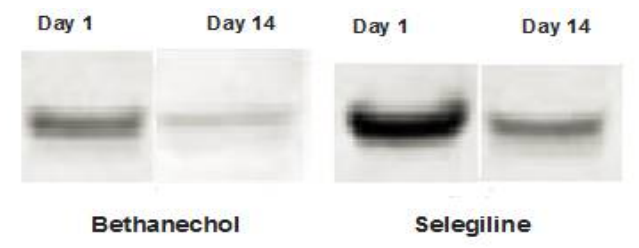

Figure 4: Expressions of $\mathrm{AChE}$ and $\mathrm{MAO}$ in cortex regions after treatment with acetyl choline agonist and MAO A inhibitor group

\section{DISCUSSION}

It has been reported that the cholinergic and monoaminergic transmission in CNS plays an important role in controlling motor functions [912]. The understanding of cholinergic and monoaminergic transmission involvement in spinal cord injury is important to for an accurate treatment for spinal cord injury. The present preclinical investigation is the first study to compare the effect of bethanechol (muscarinic receptor agonist) with selegiline (mono-amine oxidase inhibitor type B [MAOB-I]) in amelioration of 
spinal cord injury in rat model of spinal cord injury to confirm whether targeting central nervous system pathway - cholinergic or monoaminergic helps in recovering motor functions after spinal cord injury. The results of current study showed that the bethanechol (muscarinic receptor agonist) was more effective when compared to selegiline in improving motor function and promoting recovery of SCl. However, the difference was not statistically significant. Bethanechol and selegiline improved motor function by improving cholinergic and monoaminergic transmission, respectively.

Decrease in cortical cholinergic and monoaminergic transmission was observed in $\mathrm{SCl}$ rats treated with vehicle. In $\mathrm{SCl}$ rats, there was significant decrease in activity of cholinergic receptors, which led to reduction in motor function associated with the cholinergic receptor or neurotransmitter in $\mathrm{SCl}$. Cholinergic receptor function was impaired in the $\mathrm{SCl}$ rats, which was reversed after treatment with bethanechol and selegiline. Also, lower retention time was observed in rats treated with vehicle when compared to bethanechol and selegiline at all rotations (10, 15 and $25 \mathrm{rpm})$. In rotarod test, significantly less retention time was observed in $\mathrm{SCl}$ rats treated with vehicle as compared to the $\mathrm{SCl}$ rats treated with bethanechol and selegiline at all rotations. This indicates that treatment with bethanechol and Selegiline improve motor function in SCl rats. However, improvement was numerically greater in rats treated with bethanechol when compared to selegiline. This indicates that drug targeting cholinergic (muscarinic) and monoaminergic transmission would be effective in reversing motor impairment caused by SCl.

The results of this study showed that pharmacological therapy targeting cholinergic (muscarinic) and monoaminergic transmission could be a better treatment option among the patients with $\mathrm{SCl}$ and suffering from motor impairment. The result of present study encourages conducting the efficacy and safety of pharmacological therapy based on muscarinic receptor agonist in future clinical trials in $\mathrm{SCl}$ patients. In addition, it was observed that the activity of AChE was significantly impaired in SCl rats treated with vehicle. This indicates that activation of cholinergic receptors in cortex region of $\mathrm{SCl}$ rats would be effective in improving motor function [13-15]. Defects in motor function in $\mathrm{SCl}$ are possibly due to impaired transmission of cholinergic and monoaminergic pathways. The role of cholinergic receptors and monoaminergic pathways in regulating spinal cord functions have been previously reported [2,15-17].

Muscarinic receptors in CNS are associated with the regulation of learning and memory, and are also involved in controlling several sensory, motor, and autonomic routes. Muscarinic receptor of acetylcholine plays a vital role in functioning of sensory and motor structures $[2,17]$. These results indicate that impairment of cholinergic and monoaminergic transmission acts as one of key contributors to motor deficits in $\mathrm{SCl}$. Thus, cholinergic and monoaminergic system may be a useful target for effective treatment option for motor deficits associated with SCl. In summary, the present study found new therapeutic target - muscarinic receptor agonist mono-amine oxidase inhibitor type $B$ was found effective to recover motor deficit in SCI. The results of this study recommended that there is need to target - cholinergic and monoaminergic CNS pathways for developing effective treatment for SCl.

\section{CONCLUSION}

Bethanechol and selegiline are effective in ameliorating motor function deficit caused by spinal cord injury in rats. Both drugs also improve motor function in SCl rats. Thus, drugs targeting cholinergic (muscarinic) and monoaminergic transmission would be effective in reversing the motor impairment caused by SCl.

\section{DECLARATIONS}

\section{Acknowledgement}

The present study was supported with funds from the Health Department of Shandong Province of China (grant nos. 2011QW008 and 2015WS0375).

\section{Conflict of interest}

No conflict of interest is associated with this work.

\section{Contribution of authors}

We declare that this work was done by the authors named in this article and all liabilities pertaining to claims relating to the content of this article will be borne by the authors. Guangliang Fan and Jinli Luan contribute to this work equally. Both Guangliang Fan and Jinli are the first author. Xiankuo Tang did statistical analysis and interpreted the data. This whole work is supervised by Qimin Song. 


\section{Open Access}

This is an Open Access article that uses a funding model which does not charge readers or their institutions for access and distributed under the terms of the Creative Commons Attribution License (http://creativecommons.org/licenses/by/ 4.0) and the Budapest Open Access Initiative (http://www.budapestopenaccessinitiative.org/rea d), which permit unrestricted use, distribution, and reproduction in any medium, provided the original work is properly credited.

\section{REFERENCES}

1. Dong $Y$, Dobkin $B H$, Cen $S Y, W u A D$, Winstein CJ. Motor cortex activation during treatment may predict therapeutic gains in paretic hand function after stroke. Stroke 2006; 37: 1552-1555.

2. James K, Wamsley MS, Lewis W, Scott Y, Michael JK. Autoradiographic localization of muscarinic cholinergic receptors in rat brainstem. J Neurosci 1981; 1: 176-191.

3. Saltarelli MD, Lowenstein PR, Coyle JT. Rapid in vitro modulation of $[3 \mathrm{H}]$ hemicholinium-3 binding sites in rat striatal slices. Eur J Pharmacol 1987; 135: 35-40.

4. Scatchard $G$. The attractions of proteins for small molecules and ions. Ann N Y Acad Sci 1949; 51: 660 672.

5. Ward NS, Brown MM, Thompson AJ, Frackowiak RS. Neural correlates of motor recovery after stroke: a longitudinal fMRI study. Brain 2003; 126: 2476-2496.

6. Patrick F, Armin C, Karl F, Alan T. Tracking Changes following Spinal Cord Injury Insights from Neuroimaging. Neuroscientist 2013; 19: 116-128.

7. Jiang $H$, Zhang J, Zhu $H$, Li H, Zhang $X$. Nerve growth factor prevents the apoptosis-associated increase in acetylcholinesterase activity after hydrogen peroxide treatment by activating AktActa Biochim Biophys Sin 2007;39: 46-56.

8. Committee for the Purpose of Control and Supervision on Experiments on Animals. CPCSEA guidelines for laboratory animal facility. Indian J Pharmacol 2003; 35: 257-274

9. Kuhar MJ, Murrin LC. Sodium-dependent, high affinity choline uptake. J Neurochem 1978; 30: 15-21.

10. Kus L, Borys E, Ping Chu Y, Ferguson SM, Blakely RD, Emborg ME, Kordower JH. Distribution of high affinity choline transporter immunoreactivity in the primate central nervous system. J Comp Neurol 2003; 463: 341357.

11. Levine RR, Birdsall NJM. Pronounced pharmacologic deficits in M2 muscarinic acetylcholine receptor knockout mice. Life Sci 1997; 60: 963-1207

12. Lotze M, Markert J, Sauseng P, Hoppe J, Plewnia C, Gerloff $C$. The role of multiple contralesional motor areas for complex hand movements after internal capsular lesion. J Neurosci 2006; 26: 6096-6102.

13. Wessler I, Kirkpatrick CJ. Acetylcholine beyond neurons: the non-neuronal cholinergic system in humans. $\mathrm{Br} J$ Pharmacol 2008; 154: 1558-1571.

14. Yamamura HI, Synder G. Muscarinic cholinergic binding in rat brain. Proc Natl Acad Sci USA 1974; 71: 17251729.

15. Zaninetti $M$, Tribollet $E$, Bertrand D, Raggenbass $M$. Presence of functional neuronal nicotinic acetylcholine receptors in brainstem motoneurons of the rat. Eur $J$ Neurosci 1999; 11: 2737-2748.

16. Scatchard $G$. The attractions of proteins for small molecules and ions. Ann N Y Acad Sci 1949; 51: 660672

17. Zaninetti $M$, Tribollet $E$, Bertrand $D$, Raggenbass $M$. Presence of functional neuronal nicotinic acetylcholine receptors in brainstem motoneurons of the rat. Eur $J$ Neurosci 1999; 11: 2737-2748 